\title{
Assessing the quality of reproductive health services
}

Raeda Al Qutob

Salah Mawajdeh

Laila Nawar

Salama Saidi

Firas Raad

Follow this and additional works at: https://knowledgecommons.popcouncil.org/departments_sbsr-rh

Part of the Demography, Population, and Ecology Commons, Health Services Research Commons, International Public Health Commons, and the Women's Health Commons How does access to this work benefit you? Let us know!

\section{Recommended Citation}

Al Qutob, Raeda, Salah Mawajdeh, Laila Nawar, Salama Saidi, and Firas Raad. 1998. "Assessing the quality of reproductive health services," Policy Series in Reproductive Health. Cairo: Reproductive Health Working Group. 


\section{ASSESSING THE QUAUTY OF REPRODUCTIVE HEALTH SERVICES}

\section{THE POLICY SERIES IN REPRODUCTIVE HEALTH}

No. 5

Raeda Al-Qutob

Salah Mawajdeh

Laila Nawar

Salama Saidi

Firas Raad 


\section{ASSESSING THE QUALITY OF REPRODUCTIVE HEALTH SERVICES}

\section{THE POLICY SERIES IN REPRODUCTVE HEALTH}

\section{No. 5}

Raeda Al-Qutob, $M D, D R . P H$

Maternal and Child Health

Salah Mawajdeh, $M D, D R . P H$

Health Policy and Management

Laila Nawar, $P h \cdot D$

Demography

Salama Saidi, $P h . D$

Demography

Firas Raad, MA, M.P.H.

Public Health 
The Population Council seeks to improve the well-being and reproductive health of current and future generations around the world and to help achieve a humane, equitable, and sustainable balance between people and resources.

The Council, a nonprofit, nongovernmental research organization established in 1952, has a multinational Board of Trustees; its New York headquarters supports a global network of regional and country offices.

The Policy Series in Reproductive Health is produced by the Reproductive Health Working Group housed in the Population Council Regional Office for West Asia and North Africa, P O Box 115, Dokki, Giza, Egypt

\section{(C) Copyright 1998}

Population Council

Design Consultant:Fadia Badrawi

Printing Supervision:Bakr El-Gallas 


\section{TABLE OF CONTENTS}

Preface: The Policy Series in Reproductive Healith TV

Acknowledgments $\quad$ V

Abstract $\quad$ VI

INTRODUCTION 1

DEFINING "QUALITY " 2

QUALITY IN THE CONTEXT OF REPRODUTIVE HEALTH SERVICES 3

A CONCEPTUAL FRAMEWORK FOR ASSESSING QUALITY IN REPRODUCTIVE HEALTH SERVICES

Stages of the Health Care Continuum

The Components of Quality

PUTTING THE FRAMEWORK INTO OPERATION $\quad \mathbf{8}$

The Preparatory Stage

Methods of Data Collection

The Country Studies

Illustration of Methodological Approach - Jordan Study

FINDINGS

Management

Technical Competence

Information Exchange

Woman - Provider Relationship

Continuity and Follow-up

CONCLUSION

References

Appendix I Assessment of the Quality of Prenatal Care :

Structure / Manager Interview Questionnaire

Appendix I: Assessment of the Quality of Prenatal Care :

Structure / Provider Interview Questionnaire

Appendix III: Assessment of the Quality of Prenatal Care :

Woman Home Interview

Appendix IV: Assessment of the Quality of Prenatal Care :

Health Center Observation Check-List 


\section{Preface}

\section{THE POLICY SERIES IN REPRODUCTIVE HEALTH}

Papers in the Policy Series in Reproductive Health aim at sharing research undertaken by members of the Reproductive Health Working Group with policy makers, program managers and health advocates in the region, the developing world and the international community. The Reproductive Health Working Group (RHWG) was established in 1988 as part of a Special Program on the health of women and children within the context of the 'family and community initiated by the Population Council's Regional Office for West Asia and North Africa (WANA) region. The Working Group includes professionals with specialization in anthropology, biostatistics, demography, medicine, public health and sociology, residing in various countries of the region.

The Working Group delineated three key issues which were considered as central to women's reproductive health in the WANA region: first, women's physical health in terms of morbidity conditions related to the reproductive function; second, women's perceptions of their health and their dignity in relation to reproduction; and third, on the health service side, the quality of reproductive health services directed at women. The Working Group has been undertaking studies addressing these issues in countries of the region since 1989. Further research interests are currently emerging concerned with developing an intervention framework to improve reproductive health within primary care settings, and with investigating physicians' perceptions of women's health.

The Policy Series in Reproductive Health and Monographs in Reproductive Health are two complementary publications issued by the Reproductive Health Working Group. Monographs in Reproductive Health present original research, reviews of literature and theoretical discussions. They address researchers and students primarily and aim to contribute to advancement of interdisciplinary approaches in research on reproductive health. Papers in the Policy Series in Reproductive Health reach out with frameworks, methodologies and evidence of research to policy makers, program managers and health advocates, bringing out interdisciplinary perspectives. In this way they aim to contribute to the development of more holistic policy approaches that can better meet the health needs of women in the developing world. 


\section{ACKNOWLEDGMENTS}

The study authors would like to acknowledge the valuable comments and input provided by Dr. Huda Zurayk, the coordinator of the RHWG, on the several revisions of this paper. The study communities in Jordan, Egypt and Tunisia and all team members who participated in these studies are deeply acknowledged.

The authors acknowledge with thanks the valuable editorial assistance of Jan Amin. They also wish to thank Karima Khalil for her useful comments on the manuscript.

The MEAwards Program of the Population Council has provided grants to the Jordan and Tunisia studies. 


\section{ABSTRACT}

The paper offers a broad definition of quality of care, presents a comprehensive conceptual framework for the assessment of quality of reproductive health services and methodological approaches for its measurement. It presents three studies that were conducted between 1990 and 1991 by members of the regional Reproductive Health Working Group (RHWG) from Jordan, Egypt and Tunisia. The studies provide examples of applications of the framework and its measurement using multiple data sources. Selected findings are presented to illustrate comparative results between countries. Based on the lessons learned from the studies, examples of reproductive health interventions that may improve the quality of care are presented.

Keywords: Quality, women's reproductive health, Jordan, Tunisia, Egypt, women's health, health services research. 


\section{INTRODUCTION}

The growing interest in the quality of reproductive health services over the last decade has emanated from a concern with the high levels of maternal mortality and morbidity in developing countries. Health professionals and organizations working in the developing world are now actively seeking more effective ways to prevent maternal deaths and improve women's health care'.

Quality health services in the developed world have been realized through an accumulation of improvements in the delivery of services as well as in the overall strengthening of medical education policies in terms of requirements for admission to medical school, curricula development and licensing ${ }^{2}$. The Same concern for quality health services in developing countries has not yet fully emerged as a priority for policy makers due to competing demands on limited health care resources. Quality health care is equated with technical sophistication and thus considered expensive.

Improving the quality of reproductive health services requires identifying the basic 'ingredients' of quality health care. In order to make improvements one must determine what constitutes quality and how it could be measured. The paper at hand addresses these issues and is a product of a research process set in motion by the Reproductive Health Working Group (RHWG) in the West Asia and North Africa region. A subgroup was set up to conceptualize and develop a framework for quality of care in consultation with the members of the RHWG. As a result studies were conducted on reproductive health services in three separate countries of the region (Jordan, Egypt and Tunisia). The Jordan study assessed the quality of prenatal care services while the quality of family planning services was assessed by the two studies conducted in Egypt and Tunisia $3,4,5,6,7,8$.

In this paper, we offer a broad definition of quality and present a conceptual framework and methodological approaches for measuring quality of 
reproductive health services, based on these three studies. We present selected findings from

the studies, and provide some examples of repoductive health interventions that may improve quality.

\section{DEFINING 'QUALITY'}

Available literature on medical and health care research includes various formulations for defining and capturing the essence of 'quality'. Among the earliest and most prominent are Donabedian's explorations of a definition and of the process involved in the provision of quality care'. His pioneering work helped to systematize thinking on the multi-layered aspects of 'quality' in health services.

The concept of quality, as defined by Donabedian, is a 'property' or characteristic of medical care. This characteristic can rang from one end of the spectrum to the other (e.g. low to high quality care) and can manifest itself through various elements or "attributes". The first category of attributes includes the technical aspects of care and the human context in which it is provided.

How medical science is applied technically to cure medical problems and to promote human health falls under the technical domain. To complement the technical application of that science (cure) comes the equally important human setting (care) in which that science is applied. The "human setting" pertains to the nature of the patient-provider relationship i.e. whether the patient finds the provider understanding, courteous, informative, and respectful of privacy. If the patient does perceive the provider as described above, and the provider is technically competent, the interpersonal aspects of care will blend with the technical ones to increase the probability of a positive outcome for patients' health.

The second category of attributes, according to Donabedian, goes beyond the technical/interpersonal frame and includes accessibility and continuity. Accessibility refers to the structure and location of care. It assumes clear 
and well-defined 'points of entry' (e.g. emergency services) and whenever possible round-

the-clock services; it also assumes that services can be provided at a reachable distance and affordable cost. Continuity implies a coherent pattern of services between and within various health delivery systems.

Another significant contribution to understanding the definition of quality, particularly in terms of family planning services, comes from Bruce ${ }^{10}$. Her broad definition includes the ways in which individual users are treated by the system. Bruce has identified a framework which encompasses six fundamental elements crucial to the quality of family planning services if clients' demands and expectations are to be fully met. These elements include technical competence, provider-client information flow, choice of methods, interpersonal relations, follow-up and continuity mechanisms, and the appropriate constellation of services. This model, developed by Bruce, has spurred interest in the different elements of quality in reproductive health-care services.

The framework presented in this paper and applied in the three illustrative studies on the quality of care of reproductive health services has adopted elements from both Donabedian and Bruce. It has developed their definitions further by adding management of the service facility as one component of the quality of care $e^{5,8}$

\section{QUALITY IN THE CONTEXT OF REPRODUCTIVE HEALTH SERVICES}

The WHO definition of reproductive health extends beyond the physical aspects of health to include mental and social well-being. A quality service attempts to capture all aspects of the definition. This means that reproductive health service programs must take into account the social context in which women live" . Especially relevant are women's position in 
the hierarchy of family relationships, their role in the family, their workload, their contribution to decision-making, and their ability to pay for services, all of which affect women's potential to seek care and to comply with the health care provided. Addressing the socio-cultural determinants of women's health" thus becomes a necessary part of any quality health service. Studying the components of quality must be sensitive to the social context, such as the woman-provider relationship and information exchange, can increase our understanding of the health services factors influencing health-seeking behavior, and can provide insight into the more successful preventive and curative approaches to reproductive health. This understanding can help the health service manager formulate interventions to make their health facilities more socially acceptable and accessible to women users.

Assessing quality in reproductive health services means, inter alia, measuring the gap between the quality of care as perceived by the providers and as perceived by the women users ${ }^{13}$. For instance, quality care to some providers may mean impersonal 'efficient' care, which reduces mortality and morbidity. Less attention is given to women's perception and experience of illness such as daily discomforts which are not identified as major problems. It is often precisely those daily discomforts which influence her health-seeking behavior. Thus a quality service ought to give special emphasis to women's experiences, expectations, and level of satisfaction with the service, to complement the views of the providers of care.

\section{A CONCEPTUAL FRAMEWORK FOR ASSESSING QUALITY IN REPRODUCTIVE HEALTH SERVICES}

\section{Stages of the Health Care Continuum}

The framework adopted by the three illustrative studies on quality of care views Reproductive health service delivery within a continuum of services 
which begins with a structure and is fulfilled through a process. The end result of these services is the outcome.

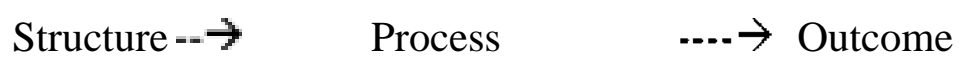

The three studies applied Donabedian's definition of the continuum of medical care to reproductive health services in the following manner:

1. The Concept of 'Structure': was considered to encompass the stable features of the providers of reproductive care, the tools and resources at their disposal, and the physical and organizational settings in which they work. Thus, structure includes the human, physical and financial resources that are used to provide reproductive health care

2. The Concept of 'Process': is defined as the set of activities that take place between the provider and woman. It refers to the actual transaction in which the provider of care makes use of the available structural elements, described above, to manage the technical and personal aspects of health.

3. The Concept of 'Outcome':includes swo elements: the direct impact of treatment on the current or future health of a woman or her newborn, and the indirect impact on her satisfaction with the services offered and her health-seeking behavior.

All three studies used women's satisfaction with service delivery as an outcome indicator. Although this indicator is influenced by women's expectations and their previous experiences, it was deemed appropriate to use this outcome indicator because subtle changes in the quality of care can be detected in women satisfaction long before the physical changes in health status can be seen ${ }^{4}$. It was assumed that a satisfied woman user would probably benefit more from the care offered to her than anunsatisfied woman. 


\section{The Components of Quality}

The illustrative studies defined components of quality in relation to reproductive health services within the three stages of the health care continuum (structure, process and outcome). The components and their working definitions were as follow ${ }^{3}$.

10 Management: refers to the set of all activities within the health care facilities through which the available human, physical, and financial resources are utilized efficiently to produce a given planned output.

20 Woman- Provider Relationship: describes an interpersonal link between the provider and the woman. This link is supposed to be established and maintained by a "considerate, courteous, and understanding" provider who possesses good listening skills and cares for the woman in a "respectful" way and in a private environment.

30 Provider Competence: refers to the qualifications and experiences of the providers as well as to the ways in which they use their technical knowledge and skill to provide women with the optimal promotional, preventive and curative care.

4. Information Exchange: describes the flow of health information between the provider and the woman recipient of care. This component is intertwined closely with the component of technical competence and the woman-provider relationship.

50 Continuity: refers to a set of mechanisms that strengthen the progress of care including referrals and promoting regular utilization of services.

The measurement of these components required the development of qualitative and quantitative indicators. The illustrative studies developed such indicators to represent components often split into sub-components. As an illustration of the process, Figure 1 presents examples of measurable indicators of the components of the quality of prenatal care used in the Jordan Prenatal Care Study ${ }^{3}$. 
Figure 1: Examples of the components, sub-components and indicators of quality of prenatal care at the three levels of health care continuum

\begin{tabular}{|c|c|c|c|c|}
\hline \multirow[b]{2}{*}{ Component } & \multirow[b]{2}{*}{ Subcomponent } & \multicolumn{3}{|c|}{ Level of care continum } \\
\hline & & Structure & Process & Outcome \\
\hline $\begin{array}{l}\text { I- Adminis-razive } \\
\text { Management }\end{array}$ & $\begin{array}{l}\text { - Planning } \\
\text { - Organizing } \\
\text { - Directing } \\
\text { - Control }\end{array}$ & $\begin{array}{l}\text {-Availability o: job } \\
\text { descriptions }\end{array}$ & $\begin{array}{l}\text {-Performs task } \\
\text { anaîsis } \\
\text { of providers }\end{array}$ & $\begin{array}{l}\text { - Womer satisfaction } \\
\text { with scheduled } \\
\text { hours }\end{array}$ \\
\hline $\begin{array}{l}\text { II-Pregoant- } \\
\quad \text { Provider } \\
\quad \text { Relationship }\end{array}$ & $\begin{array}{l}\text { - courtesy } \\
\text { - Understanding } \\
\text { - Communication } \\
\text { - Consideration } \\
\text { - Erivacy } \\
\text { - Respect }\end{array}$ & $\begin{array}{l}\text { - Arailability of } \\
\text { policies } \\
\text { to ensure } \\
\text { privacy during } \\
\text { encounters }\end{array}$ & $\begin{array}{l}\text {-Proper personal } \\
\text { treatment } \\
\text { of women }\end{array}$ & $\begin{array}{l}\text { - Women satisfaction } \\
\text { with providers } \\
\text { attitude } \\
\text { and personal treatment }\end{array}$ \\
\hline $\begin{array}{l}\text { 111-Technical } \\
\text { Management }\end{array}$ & $\begin{array}{l}\text { - High risk } \\
\text { screening } \\
\text { - Management of } \\
\text { complicated } \\
\text { pregnancies } \\
\text { - Monitoring }\end{array}$ & $\begin{array}{l}\text {-Qualification of } \\
\text { staff and pre- } \\
\text { requisite training } \\
\text { in maternity care }\end{array}$ & -High risk screening & $\begin{array}{l}\text { - women satisfaction } \\
\text { with indicators of the medica } \\
\text { management provided }\end{array}$ \\
\hline $\begin{array}{l}\text { IV-Information } \\
\text { Transmission }\end{array}$ & $\begin{array}{l}\text { - Discussion of } \\
\text { pregnancy } \\
\text { related } \\
\text { information }\end{array}$ & $\begin{array}{l}\text {-Availability of } \\
\text { polscias } \\
\text { of health } \\
\text { education }\end{array}$ & $\begin{array}{l}\text { - Proper communication } \\
\text { techniques in } \\
\text { transferring } \\
\text { pregnancy related } \\
\text { information }\end{array}$ & $\begin{array}{l}\text {-women satisfaction } \\
\text { with provided } \\
\text { information }\end{array}$ \\
\hline V-Continuity & $\begin{array}{l}\text { - Eacilitation } \\
\text { - Delection } \\
\text { - Correction }\end{array}$ & $\begin{array}{l}\text {-Availability of } \\
\text { poicies Car home } \\
\text { vist }\end{array}$ & $\begin{aligned} \text {-Keeping } & \text { proper } \\
\text { medical } & \text { records }\end{aligned}$ & $\begin{array}{l}\text { - Women satisfaction } \\
\text { with being able to see } \\
\text { the same provider } \\
\text { when needed }\end{array}$ \\
\hline
\end{tabular}

Source: A1-Qutob R., Yawajdeh S., Raad F. The assessment of reproductive health services: A conceptual framework for prenatal care. Sealth Care for Women International, 17: 423-434, 1996. 


\section{PUTTING THE FRAMEWORK INTO OPERATION}

\section{The Preparatory Stage}

In the preparatory stage, methods for collecting data appropriate for measuring quality of care indicators for the three studies were developed This process involved considerable interaction between the study investigators and the multi-disciplinary members of the RHWG, informally and through the organization of workshops. The adoption of a combined bio- medical and socio-behavioral

framework allowed for a multiplicity of methods to be used for the assessment of quality of care including quantitative and qualitative approaches.

Long and detailed preparations and the field testing of instruments took place during this stage, beginning in the fall of 1989. These activities included a thorough literature review of methodologies that have been used in studying reproductive health services, adjusting them to particular types of service and to the cultural contexts involved, as well as conducting exploratory studies in some study sites. The exploratory studies helped in testing the feasibility of applying certain techniques and also the logistics and resources required, in order to determine the advantages and disadvantages of alternative methods in actual field settings. One example illustrating the importance of such exploratory studies is seen in the initial findings of the Jordan Prenatal Care pilot study which indicated that facility exit interviews of women carried out by medical personnel could not capture variabilities in women's satisfaction with the service provided. Home interviews conducted by trained social science interviewers proved more successful in showing variability in women's satisfaction with the care provided. Furthermore, it was found that women felt more at ease and responded more easily to questions when the interview took place in their own home environment as compared to the health facility.

The methods and results of exploratory studies were shared and discussed with the larger multi-disciplinary RHWG in two meetings in Cairo during January and November, 1990. The input and feedback provided by members 
of the RHWG led to further modification and adaptation of the study protocols and instruments into their final form

\section{Methods of data collection}

The Jordan study, conducted in 1990, used multiple methods to collect data from various sources (Tablel). Providers' views were elicited by direct interviewing of managers. This yielded information for the evaluation of the capacity of the facility to provide services (infrastructure, manpower, resources, attitudes, accessibility, availability, ..etc.). In addition, it was considered important to gather information on women's view and women were interviewed at home for that purpose. Because the reports of both providers and of women users about the process of care delivery could be subjective, facility observation was also used to provide information on the way services were being delivered (process).

As such, the three illustrative studies were undertaken using the following two methods with the extent of application being dependent on logistics and feasibility.

a Quantitative methods including data collection by personal interview with women, health-care managers and providers.

b. Qualitative methods in the form of observation of facilities of service delivery.

\section{The Country Studies}

\section{The Egypt Study}

The Egypt study, which was conducted in 1990, assessed the quality of family planning services by using the methods presented in Table $2^{7}$. The study community consisted of 9 governorates. Selection of governorates was based on two criteria, the first being a balanced geographical representation of metropolitan, upper and lower Egypt, and the second being an adequate representation of levels of contraceptive prevalence as determined in the Egypt Demographic and Health Survey ${ }^{14}$. 
Table 1. Data collection methodologies used to obtain information on health care continuum by components of quality of care (Jordan Study)

\begin{tabular}{|c|c|c|c|}
\hline \multirow{2}{*}{ Components } & \multicolumn{2}{|c|}{ Health Care } & Continuum \\
\hline & Structure & Process & Outcome \\
\hline Management & $M / \supseteq I, F O, C I$ & $\mathrm{FO}, \mathrm{CI}$ & CI \\
\hline Information exchange & $M / P I, F O, C I$ & $\mathrm{FO}, \mathrm{CI}$ & CI \\
\hline Continuity of care & $\mathrm{M} / \mathrm{PI}, \mathrm{FO}$ & $\mathrm{FO}, \mathrm{CI}$ & $\mathrm{CI}$ \\
\hline Technical competence & $\mathrm{M} / \mathrm{PI}, \mathrm{FO}$ & $\mathrm{FO}, \mathrm{CI}$ & $\mathrm{CI}$ \\
\hline Client provider relationship & $\mathrm{H} / \mathrm{PI}, \mathrm{FO}, \mathrm{CI}$ & $\mathrm{FO}, \mathrm{CI}$ & $\mathrm{CI}$ \\
\hline Management & MI & $\mathrm{CI}$ & CI \\
\hline
\end{tabular}

M/PI: Manager and or Provider Interview

FO: Facility Observation

$\mathrm{CI}$ : Client (pregnant women) Interview 
In each of the ten governorates, five administrative divisions were selected. Selection of clinics within these administrative divisions was made with proportional representation of geographic location (urban-rural) and type of clinic/unit belonging to the Ministry of Health $(\mathrm{MOH})$, the Clinical Service Improvement (CSI) project of the $\mathrm{MOH}$, or the Egyptian Family Planning Association (EFPA). The resulting sample consisted of 120 family planning units representing 7 percent of the clinics operating in the 9 Governorates. Of these 120 clinics, 61 units were located in rural and 59 in urban areas The 'majority, 90 clinics, were run by the $\mathrm{MOH}$; 25 were operated by the EFPA; and the remaining 5 clinics belonged to the CSI project.

The study further selected women for interview both from local communities served by the clinics and from the clinics themselves. A sampling frame was constructed of currently married women below the age of 50, and the sample of women from the community included users of the services of private doctors,

hospitals and pharmacies, as well as those who were not using any type of family planning services. The latter group (12 non-users living around each of the clinics selected) was included in order to obtain information on past experience, if any, with the types of clinics surveyed. The women selected from the community represented three groups in the following order:

- 4 current users of contraceptives from private sources

- 6 current non - users, but past users of contraceptives

- 2 never users

The sample of users from the selected clinics was drawn from the first ten women to attend each clinic over a period of three days, a total of 1188 women. The total number of women selected from the community was 1440. The number of managers/providers of all the clinics studied was 120 .

In the Egypt study three types of data-collection instruments were used:

a. Manager / provider interview

b. Women exit interview

c. Women community interview 
Table 2. Dáta collection methodologies used to obtain information on health care continuum by components of quality of care (Egypt Study)

\begin{tabular}{|c|c|c|c|}
\hline \multirow{2}{*}{ Components } & \multicolumn{3}{|c|}{ Health Care Continuum } \\
\hline & Structure & Process & Outcome \\
\hline Choice of method & MI & $\mathrm{CI}$ & $\mathrm{CI}$, WCI \\
\hline Information exchange & MI & $\mathrm{CI}$ & $\mathrm{CI}$ \\
\hline Continuity of care & MI & $\mathrm{CI}$ & $\mathrm{CI}$ \\
\hline Technical competence & MI & $\mathrm{CI}$ & $\mathrm{CI}$ \\
\hline Client provider relationship & MI & $\mathrm{CI}$ & $\Gamma I, W C I$ \\
\hline Constellation of services & MI & $\mathrm{CI}$ & Cl. WCI \\
\hline
\end{tabular}

MI: Manager Interview

CI: Client Interview

WCI: Women Community Interview 


\section{The Tunisia Study}

In the Tunisia study, conducted in 1991, family planning services in three Tunisian cities, Sousse, Sfax, and Kairouan, were assessed using several methods (Table 3$)^{8}$. The study population included family planning clinics run by the Ministry of Health $(\mathrm{MOH})$ and the Tunisian Family Planning Association (TFPA). In each city, two clinics were studied. One clinic run by the Tunisian Ministry of Health and the other one run by the Tunisian Family Planning Association. The sample included new clients, old clients with no problems related to family planning, and old clients with some problems linked to family planning. The sample included 15 clients in each category resulting in a study sample of 90 clients in each city, a total of 540 women altogether.

Managers providers of care in the selected $\boldsymbol{6}$ facilities were also included in the study. Their inclusion provided information on the structure and readiness of the clinic to provide quality services to clients The six clinics were observed by specially trained research assistants who obtained information on clinic structure and client - provider interaction.

In the Tunisia study, data collection instruments included:

a* Manager/Provider interview

b. Client interview

co Facility observation

\section{The Jordan Study}

The Jordan study ${ }^{6}$, assessed the quality of prenatal care services in public Maternal and Child Health (MCH) facilities in the area of Irbid Governorate situated in northern Jordan. At the time of the study, the area studied had a population of approximately 450,000 including both urban and rural sectors. Forty five percent of the population lived in Irbid city and the rest in the surrounding areas. Prenatal care in the study area is mainly provided by the 
Table 3. Data collection methodologies used to obtain information on health care continuum by components of quality of care (Tunisia Study)

\begin{tabular}{|c|c|c|c|}
\hline \multirow{2}{*}{ Components } & Health & \multicolumn{2}{|c|}{ Care Continuum } \\
\hline & structure & Process & Outcome \\
\hline Choice of method & $M / P I$ & $\mathrm{FO}, \mathrm{CI}$ & CI \\
\hline Information exchange & $M / P I$ & $\mathrm{FO}, \mathrm{CI}$ & CI \\
\hline Continuity of care & $M / P I$ & $\mathrm{FO}, \mathrm{CI}$ & CI \\
\hline Technical competence & $M / P I$ & $\mathrm{FO}, \mathrm{CI}$ & CI \\
\hline Client provider relationship & $M / P I$ & $\mathrm{FO}, \mathrm{CI}$ & CI \\
\hline Constellation of services & MIPI, FO & $\mathrm{FO}, \mathrm{CI}$ & CI \\
\hline Management & $\mathrm{MIPI}, \mathrm{FO}$ & $\mathrm{FO}, \mathrm{CI}$ & CI \\
\hline
\end{tabular}

MIPI: Manager àd/or Provider Interview

FO: Facility Observation

$\mathrm{CI}$ : Client Interview 
public sector (over 80 percent), complemented by the private, military and United Nations Relief and Works Agency (UNRWA) services. Public sector provision of prenatal care is delivered through Maternal and Child Health facilities which sometimes consist of separate facilities and sometimes of units integrated within Primary Health Care centers (PHC).

The total number of $\mathrm{MCH}$ facilities providing prenatal care in the study community was thirtyone. Irbid city itself had five separate $\mathrm{MCH}$ facilities, as compared to twenty-six located within PHCs in the surrounding area. Each facility in the surroundings of Irbid serves a well defined population.

The sample included the managers of all facilities (31) and the providers of prenatal care within the facilities, all of whom were interviewed. Due to the logistic difficulties encountered in observing all the $\mathbf{3} 1$ facilities, only ten $\mathrm{MCH}$ facilities were selected, all the five city centers as well as five selected at random from those in the rural areas, for facility observation. Furthermore, a total of 289 women attending the 10 observed facilities for prenatal care were selected for home interview. These included women who were receiving prenatal care during the study and women who had received prenatal care within one month of the beginning of the study.

The Jordan Study used the following data-collection instruments:
a. Manager interview
b. Provider interview
c. Women home interview
d. Facility observation

\section{Illustration of Methodological Approach - Jordan Study}

It is useful to present in detail the methodological approach of one of the studies. Thus, we review the kind of information obtained using the different data collection instruments in the Jordan study.

\section{1 -Quantitative Data Collection}

\section{a. Interview with managers and providers}

Data from managers/providers were collected by personal interview conducted by one of the study investigators. All managers and providers were interviewed before their centers were observed. 
The manager interview instrument (Appendix I) was used to elicit information at the level of structure on the components of management, the technical competence of providers and continuity of care. Data was obtained on:

- policies adopted by the managers of health care facilities to provide quality reproductive care;

- qualifications of staff, management styles, management training and experience of the managers interviewed;

- applications of managerial functions within the settings and;

- managers' awareness of the indicators of quality reproductive health care.

The provider interview instrument (Appendix II) addressed physicians and/or midwives. Interviews elicited information at both the structure and process levels regarding awareness of the five components of quality care (see section IV/B).

\section{b. Interviews with women}

A sample of women who had visited the 10 health centersselectedfor observation was interviewed at home. The interviews took place after the health facility observation was completed. Address of eligible women were obtained from the facility record list. Interviews were conducted by welltrained researchers specialized in public health or in social sciences. Of the 289 women interviewed, only 70 were also observed.

Information was obtained by direct interview using a woman interview instrument (Appendix III) with reference to the last visit to the health facility on women's perceptions of:

- Interpersonal relationship with providers;

- Provider technical competence;

- Health information exchange;

- Continuity measures if/when provided;

- Satisfaction with care provided. 


\section{Qualitative Data Collection}

The facility observation method was used to gather qualitative data on both the structural aspects and on the actual process of health care delivery at the 10 selected health centers. The observation was conducted by one of the study investigators, a physician specialized in public health. Her qualitative observation skills were developed through her previous participation in an intensive course in Medical Anthropology and through training in qualitative data collection provided by a senior medical anthropologist, member of the RHWG. The observation included the structure of the facility, and the process of health-care delivery to women attending prenatal care services. To ensure objectivity in data collection, a checklist was prepared which included indicators of all identified quality of care components In addition, notes were kept on each observed center describing the internal structure of the facility and the process of care delivery. This was done in order to uncover any problems in the structural and organizational set-up that could not have emerged in direct interviews with managers, providers and/or women. The observation minimized bias by describing service delivery on a variety of clinic days, covering a range of pregnant women in different stages of their pregnancy. The facility observation instruments are presented in Appendix IV.

\section{FINDINGS}

Selected findings from the three studies are presented to illustrate the usefulness and policy relevance of information provided by the three studies. The findings cover all the components of quality reproductive health care at the different levels of the health care continuum. (For further details, see $3,4,5,6,7,8)$

\section{Management}

The Tunisia study revealed several noteworthy findings regarding the management of reproductive health services. The study showed that a quarter of all clinics were located in areas that were difficult to reach and that half of all clinics were housed in old buildings. Comparing the TFPA to the $\mathrm{MOH}$ clinics showed the relative strengths and weaknesses of each type 
of facility. Three-quarters (three out of four) of $\mathrm{MOH}$ clinics were well painted while only a quarter of the TFPA clinics were newly painted. The TFPA clinics, however, were all clean at the time of observation compared to only one of the MOH clinics. In addition, all the TFPA clinics had signs displaying the working hours and services provided compared to only one of the MOH clinics.

The Jordan study also revealed several interesting findings on management. Although the majority of the managers fully understood the social context within which they operated, many were unaware of several key structure and process indicators. For example, one third of the 31 managers did not know the workload of the midwife in terms of the number of pregnant women she was seeing per unit time. This workload was noted to be quite high on observation. Also, more than half of the managers did not know the status/availability of equipment and only three managers reported having job descriptions for the clinics' staff.

The findings highlight gaps in management at both the structure and process levels and show that more could be done to improve quality through small reforms in management. Admittedly it is difficult to quantify the exact contribution of these reforms to a 'quality' outcome, yet they are nonetheless important, easy to implement, and most probably would increase utilization. Furthermore, health managers could take advantage of the fact that women often had to wait a long time to see the midwife by providing valuable health education sessions while they waited.

\section{Technical Competence}

The Egypt study revealed interesting findings on technical competence at the level of structure; $20 \%$ of the practicing physicians were gynecologists and the remainder were general practitioners; $70 \%$ of the physicians were trained in family planning techniques; about $50 \%$ of them believed that the training programs could have been more effective had they been more applied and less theoretical, covering all new family planning methods, and incorporating some international expertise in family planning.

At the process stage, it is worth noting several findings from the Tunisia study. Only one third of all women users were weighed and had their blood 
pressure measured, about one half were asked about their gynecological history, and only one third were informed of the steps involved in the medical examination. It is important to note that almost none of the study women were checked for anemia.

These findings highlight the need for more effective and greater use of clinical guidelines and protocols by providers of reproductive health services.

\section{Information Exchange}

Several findings on information exchange are worth noting from the Jordan study, provided by a variety of data-collection instruments. It was found that $74 \%$ of all clinic managers believed that providers of care did not have adequate training in health education. Health education was undertaken mostly by midwives, with physicians rarely participating in the process. No audio-visual or printed material was used for demonstration. Physicians provided health information only when pregnant women inquired about health-related issues. Nutrition information lacked specificity. Behavioral problems such as smoking and medicinal drig intake were not discussed. Moreover, from the perspective of pregnant women, two third of the women receiving prenatal care expressed dissatisfaction with the quality of information; about half of those women did not know the dangerous symptoms and/or signs of pregnancy; and about $92 \%$ did not know how to behave in the event of a health problem requiring emergency care such as severe trauma or when feeling a gush of water coming out from the vagina.

Clearly health education interacts closely with two other elements of quality of care: technical competence and the women-relationship. The findings indicate a need for training in health education amongst health providers, particularly midwives. Training courses should be in-depth and comprehensive. They should make use of audio-visual aids. Most importantly they should emphasize the two-way exchange of information, with users encouraged to pose questions (expressing concerns and worries) and providers responding to those queries and anxieties in a sensitive and technically competent way. 


\section{Woman-Provider Relationship}

An important lesson emerged from the Jordan and Tunisia studies regarding the women-provider relationship: privacy and sympathetic ears are important to women interviewed expressed dissatisfaction with the degree of privacy in $\mathrm{MOH}$ clinics. Midwives would rarely pull screens or lock doors during prenatal examinations. Women also felt they were not treated with warmth and openness. They were not invited to be seated by the midwife or the physician; communication between pregnant women and the midwife focused solely on filling out the obstetric card; and women were not given a chance to air their thoughts and complaints. In Tunisia, one third of observed women were not seated and one third had to undress in non-private settings.

Reproductive health programs should take account of such matters. Privacy and warmth matter a lot to women. Moreover, certain aspects of care best handled by specific members of the health team. For example, midwives are potentially best prepared to provide communication of health information to women given the proper training. Building a close rapport with the women user is however a necessary requirement for all health providers. Health programs should prepare providers for these interpersonal aspects of care.

\section{Continuity and Follow-up}

It is clear from both the Tunisia and Egypt studies that follow-up was quite a problematic issue. In Egypt, not all family planning clinics kept medical records, and one quarter of clinics maintaining records had incomplete information. In addition, less than one-half of the clinics (43\%) reported having a system of follow-up for dropouts. In Tunisia, interviews with women revealed that none of the $\mathrm{MOH}$ clinics included home visits as a regular activity. Moreover, only $17 \%$ of women were scheduled for a follow-up appointment and it is not clear whether these women who were given a return appointment were the ones who really needed it.

Program managers can improve continuity and follow up efforts if more emphasis is placed on keeping effective medical records, and on systems to detect dropouts and promote home visitation and follow-up. 


\section{CONCLUSION}

We have put forward a broad definition of quality in reproductive health services . Building on the work of Donabedian and Bruce, five components of quality of health care were identified and discussed: management, technical competence, information exchange, women-provider relationship, and continuity and follow-up. These components provided criteria for the evaluation of the structure, process, and outcome of reproductive health services in three countries of the region. The studies illustrate how using the components as an evaluative tool can assist health program designers and managers to pinpoint weaknesses in reproductive health programs. Intervention programs focusing on the five different components of quality can then be put in place. Monitoring and evaluation of quality improvements can be done by using the indicators developed by these studies. 


\section{REFERENCES}

1. Abou Zaher, C.; Royston, E., 1991. Maternal Mortality: A Global Fact Book. Geneva: World Health Organization

2. Rakich,J.S.; Longest B.B.; K., 1994. Managing Health Services

Organizations. Health Professions Press, $3^{\text {rd }}$ Edition.

3. Al-Qutob,R.; Mawajdeh, S.;Raad, F., 1996. 'The assessment of reproductive health services: A conceptual framework for prenatal care' Healh Carefor WomenInternational, Vol. 17, pp. 423-434.

4. Mawajdeh, S.; Al-Qutob, R.; Raad, F., 1995. 'The assessment of quality of care in prenatal services in Irbid, North Jordan: Women's perspectives'. Journal of the International Development Research Center. pp. 1-18

5. Mawajdeh, S.; Al-Qutob, R., 1993. 'Assessment of the managerial functions in primary health care settings'. The Joumal of Health Administration Education. Vol. 11, No. 4 pp. 609-616.

6. Al-Qutob, R.; Mawajdeh, S., 1992-93. 'Assessment of the quality of prenatal care: The transmission of information to pregnant women in maternal and child health centers in Jordan'. International Quarterly of Community Health Education. Vol. 13, No. 1, pp. 47-62.

7. Central Agency for Public Mobilization and Statistics (CAPMAS), 1992. Assessment of Quality of Family Planning Services in Egypt. Cairo:

CAPMAS, Population Policy Studies, Occasional Paper No.2.

8. Saidi, S., 1995. Assessing the Quality of Care in Care in Family Planning Services: A Case Study in Tunisia. Report submitted to the Population Council Regional Office in Cairo.

9. Donabedian, A., 1980. 'The Definition of Quality and Approaches to its Measurements'. Volume 1 of Explorations in QualityAssessment and Monitoring. Ann Arbor, MI: Health Administration Press.

10. Bruce, J., 1990. 'Fundamental elements of the quality of care: A simple framework'. Studies in Family Planning, Vol. 21, No. 2, pp. 61-91 